Review

\title{
Design of Catalytically Amplified Sensors for Small Molecules
}

\author{
Olga V. Makhlynets * and Ivan V. Korendovych * \\ Department of Chemistry, Syracuse University, Syracuse, NY 13244, USA \\ * Author to whom correspondence should be addressed; E-Mails: ovmakhly@syr.edu (O.V.M.); \\ ikorendo@syr.edu (I.V.K.); Tel.: +1-315-443-1661 (I.V.K.); Fax: +1-315-443-4070 (I.V.K.).
}

Received: 6 February 2014; in revised form: 21 March 2014 / Accepted: 26 March 2014 /

Published: 17 April 2014

\begin{abstract}
Catalytically amplified sensors link an allosteric analyte binding site with a reactive site to catalytically convert substrate into colored or fluorescent product that can be easily measured. Such an arrangement greatly improves a sensor's detection limit as illustrated by successful application of ELISA-based approaches. The ability to engineer synthetic catalytic sites into non-enzymatic proteins expands the repertoire of analytes as well as readout reactions. Here we review recent examples of small molecule sensors based on allosterically controlled enzymes and organometallic catalysts. The focus of this paper is on biocompatible, switchable enzymes regulated by small molecules to track analytes both in vivo and in the environment.
\end{abstract}

Keywords: sensor; protein design; signal amplification; catalysis

\section{Introduction}

Small molecule sensors have a broad range of applications ranging from metal tracking in vivo to detecting chemicals in food and the environment. One common strategy for sensor design utilizes conformational switches that change their structure upon analyte binding, resulting in a change in fluorescence of reporter groups [1-11]. Another approach, which is the focus of this review, is based on catalytically amplified sensing in which allosteric [12] binding of an analyte triggers conformational changes, which in turn modulates catalysis at the active site (Figure 1A). This method effectively links a single analyte binding event with production of multiple molecules of colored and/or fluorescent product that can be easily measured. Owing to the large signal amplification, catalytically amplified sensing provides a significant sensitivity advantage over sensors that rely on fluorescence turn-on due 
to change in relative orientation of reporter groups. Some of the best-known examples of catalytically amplified sensors are enzyme-linked immunosorbent assay (ELISA) [13-15] and immuno-polymerase chain reaction (IPCR) [16,17]. ELISA is a plate-based assay designed to identify and quantify biological analytes, including proteins, peptides and hormones. While ELISA assays are not purely allosteric, they demonstrate nicely the concept of signal amplification through catalysis (Figure 1B). An antibody immobilized on a solid support selectively interacts with antigen in the liquid sample. After removal of unbound antigen the plate is treated with antigen-specific antibody conjugated to an enzyme that produces a colored or luminescent product. A variety of enzymes can be used to amplify the signal, but the most common enzyme is horseradish peroxidase (HRP) in combination with 3,3',5,5'-tetramethylbenzidine (TMB) or 2,2'-azino-bis(3-ethylbenzothiazoline-6-sulfonic acid) (ABTS), which produce colored product in the presence of $\mathrm{H}_{2} \mathrm{O}_{2}$. IPCR combines the versatility of the ELISA approach with the sensitivity of PCR. In IPCR, an antibody is linked to DNA instead of the enzyme (Figure 1B) and the signal is amplified exponentially using a polymerase chain reaction [18-20]. DNA amplicons generated by PCR can be quantified by gel electrophoresis or real-time fluorescence measurements [20,21] improving detection limit by 100-100,000-fold as compared to ELISA.

Figure 1. The general principle of analyte detection by catalytically amplified sensor (A) and comparison of ELISA and IPCR (B).

A

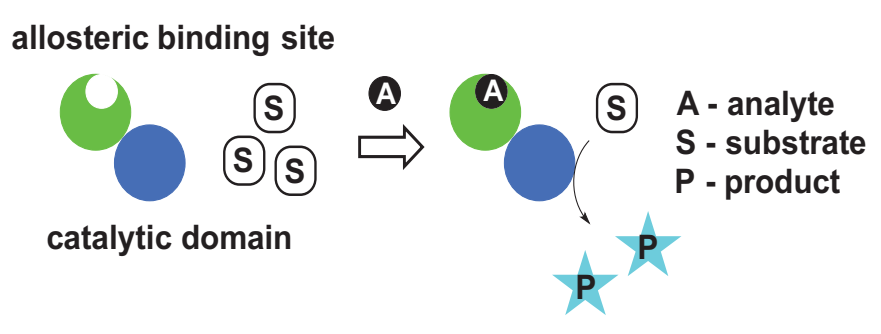

B

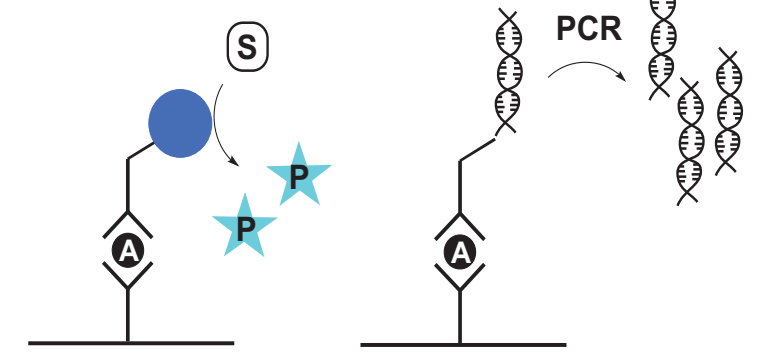

Several recent reviews [22,23] have already discussed key quantitative principles of analyte detection through signal amplification, and here we provide only a brief summary. When designing sensors one must consider such properties as detection limit, linear relationship between the analyte concentration and signal output, and the response time. For an efficient sensor the following conditions need to be met: (1) the rate of analyte binding by sensor should be faster than the rate of the reporter reaction; (2) sensor concentration should be sufficient to bind all analyte molecules; (3) low background rate when analyte is not bound; (4) extinction coefficient or quantum yield of the product should be as high as possible. In an ideal situation all analyte (A) is bound to the sensor and the readout signal (product concentration $\mathrm{P}$ ) is amplified by a factor $\mathrm{k}_{\mathrm{cat}} * \Delta \mathrm{t}$, where $\mathrm{k}_{\text {cat }}$ represents the catalyst's turnover number and $\Delta \mathrm{t}$-reaction time: $[\mathrm{P}]=\mathrm{k}_{\mathrm{cat}}{ }^{*} \Delta \mathrm{t}[\mathrm{A}]$. High $\mathrm{k}_{\text {cat }}$, high affinity of the sensor for substrate, and high extinction coefficient for colorimetric output signal or quantum yield for fluorometric output signal are essential parameters for signal amplification.

Much attention has been devoted to catalytically amplified sensors for detection of proteins and DNA [24-30]. In this review we will highlight recent examples of protein-based sensors for small molecules and compare them to organometallic catalysts that switch on upon analyte binding. 
Protein-based sensors offer several critical advantages for sensor design. First, nature has already created a multitude of proteins that recognize various ligands and catalyze many reactions with high efficiency, providing an excellent starting point for developing new sensors. Second, modern molecular biology techniques allow for easy expression and purification of large quantities of various proteins. Finally, new proteins can be designed using directed evolution to bind previously unrecognized ligands or to catalyze unnatural reactions. The field of biosensor design holds much promise for environmental control, explosives detection and therapeutic applications such as sensing disease markers, and measuring concentrations of metal ions, hormones, etc. In addition to its inherent practical value, biosensor design research advances fundamental knowledge of protein structure and function.

Many of the designs that take advantage of existing allosteric regulations have been previously reviewed [11,31-37]. Here we survey progress in sensor design as well as challenges of engineering novel binding and/or catalytic sites in non-enzymatic proteins.

\section{Signal Amplification by Protein-Based Switches}

Here we review recent examples of protein-based sensors implementing catalytic signal enhancement. Each subsection represents a different design strategy.

\subsection{Control of Enzyme Assembly}

Correct fold of enzyme is essential for its activity, therefore controlling the protein's structure is a way to modify its function. Kim et al. used this strategy to build a probe for detection of androgen receptor (AR) agonists [38,39]. Click beetle luciferase (CBLuc) was split in two parts, giving functionally inactive fragments. The ligand-binding domain of androgen receptor (AR LBD) was fused to a coactivator peptide and the resulting fusion construct was placed between the $C$-terminal and $N$-terminal parts of CBLuc (Figure 2A). Androgen receptor agonist dihydroxytestosterone (DHT) induces association between AR LBD and the peptide, bringing together the $N$ - and the $C$-terminal fragments of CBLuc thus restoring its activity (Figure 2B). CBLuc is insensitive to $\mathrm{pH}$ and metal ions and therefore provides an excellent in vivo probe. Live human cells expressing the probe produced tissue-transparent red bioluminescence signal $\sim 30$ times higher than a control upon exposure to $10 \mu \mathrm{M}$ DHT for $20 \mathrm{~min}$. After washing cells to remove DHT, the luminescence intensity decreased to background levels within $2 \mathrm{~h}$ [38]. The probe was shown to be agonist-selective and may have applications in screening for chemicals that induce AR signaling. In another study the same group developed a combination of sensors that emit characteristic red or green bioluminescence light in response to estrogen receptor agonist or antagonist, respectively [39].

\subsection{Domain Insertion}

Domain insertion creates a chimera that couples the ligand binding capability of one protein to the catalytic activity of another (this method is reviewed in detail in [37]). Usually, the guest protein is inserted into a loop of the host protein to avoid structure perturbation. The Ostermeier group has combined maltose binding protein (MBP) and $\beta$-lactamase (BLA) to create a protein switch whose catalytic activity is regulated by maltose $[40,41]$. They used circular permutation to change the 
topology of BLA by joining the original $C$ - and $N$-termini with a linker and cutting the sequence at a different site (Figure 3A). This rearrangement allowed for coupling of two unrelated proteins in order to create a catalytically amplified sensor. Screening of a library of chimeras with different permutation sites identified a switch with $\beta$-lactamase ability $\sim 600$-fold higher in the presence of maltose as compared to the background. The activity was monitored using nitrocefin (Figure 3B), a $\beta$-lactam that produces a colored product upon hydrolysis. Expression of the fusion protein in E. coli provides maltose-dependent $\beta$-lactam antibiotic resistance to the cells. This phenotype was used to create new sensors that responded to different ligands. The maltose-binding site was altered and proteins that responded to sucrose binding were selected by plating cells on ampicillin plates in the presence of sucrose (Figure 3A). Colonies from sucrose-containing plates were further screened for nitrocefin hydrolysis and one of the switches had high affinity for sucrose $(0.7 \mu \mathrm{M})$ and relatively high specificity (30-fold higher for sucrose as compared to maltose). In other studies by the Jones lab, the heme binding function of cytochrome $b$ was coupled to antibiotic degrading activity of $\beta$-lactamase to create a switch responsive to heme $[42,43]$.

Figure 2. Bioluminescent sensor for agonist detection based on complementation strategy of split CBLuc. (A) Luciferase was split in two halves that reassemble when agonist is present. The enzyme domain is in blue, the allosteric binding domain is in green, and the signal that modulates the switch is shown as a black sphere; (B) Oxidation of luciferin promoted by luciferase generates bioluminescent light.

A

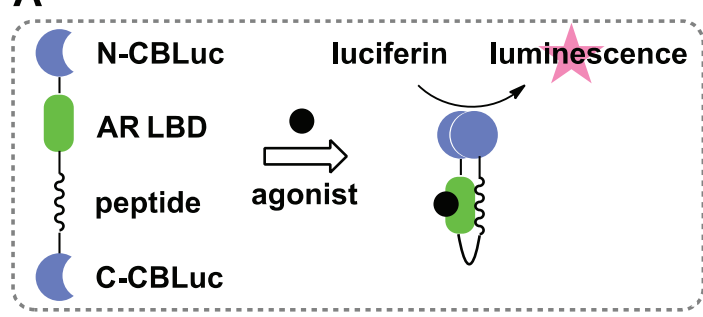

B

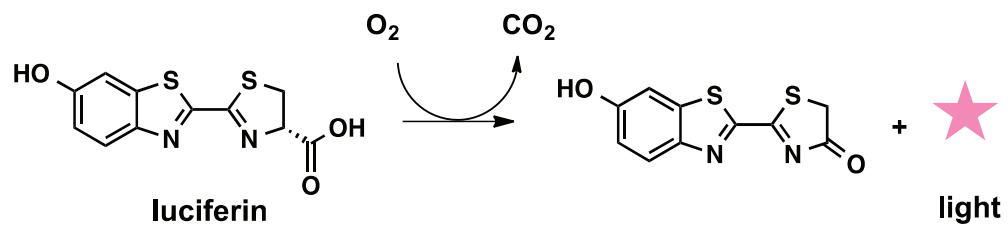

A sensor for detection of cAMP was developed by circular permutation of firefly luciferase [44]. Crystal structure of luciferase reveals that the enzyme consists of two domains connected by a hinge. Upon substrate binding the two domains rotate and assume closed conformation. The protein was subjected to circular permutation creating an inactive enzyme, where the domains cannot rotate freely around the hinge (Figure 3C). A cAMP-binding domain B from kinase regulatory subunit type II $\beta$ (RII $\beta \mathrm{B}$ ) was then fused between native $N$ and $C$ termini of luciferase through a set of linkers. Optimization of permutation site and linker size produced a construct with 70-fold increased luciferase activity in the presence of $100 \mu \mathrm{M}$ cAMP as compared to the background.

\subsection{Protein Splicing}

An intein is a part of a protein that can cut itself out, joining the remaining protein sequences by a peptide bond in a process called protein splicing. Two groups engineered sensors by insertion of a hormone binding domain into an intein, which was then inserted into a reporter protein (enzyme). Insertion of a sequence into a splicing domain abolishes splicing ability, which is then restored upon 
binding of the hormone. The subsequent protein splicing removes intein and joins two halves of the enzyme, activating its function. Buskirk et al. used estrogen receptor ligand binding domain (ER LBD) that undergoes a conformational shift upon binding of 4-hydroxytamoxifen (4-HT) placing the $N$ - and $C$-termini closer to each other [45]. This protein was inserted into Mycobacterium tuberculosis RecA intein, which in turn was inserted into $\beta$-galactosidase (Figure 4A). The $\beta$-galactosidase activity was measured by hydrolysis of X-gal, which produces a blue product (Figure 4B). Significant X-gal hydrolysis was measured only in the presence of 4-HT. The splicing ability upon 4-HT binding was also linked to a red colony phenotype in Saccharomyces cerevisiae. Ade2 enzyme is involved in the adenine biosynthesis pathway and its absence results in accumulation of a bright red byproduct. Insertion of ER-intein fusion into the gene encoding Ade2 abolished Ade2 activity as shown by formation of red yeast colonies. However, addition of 4-HT triggered Ade2 splicing, restoring enzyme activity and producing normal white cells. This sensor can serve as a tool to control protein function in living cells via a small cell-permeable molecule. Skretas et al. designed a probe whose splicing ability and thus $\beta$-galactosidase ( $\beta$-lactamase) activity were controlled in vivo by the presence of a thyroid hormone [46]. Random mutagenesis combined with genetic selection through growth phenotype produced intein that could be controlled by the presence of synthetic estrogen ligands in a dose-dependent fashion.

Figure 3. Insertion of one protein into another using circular permutation. (A) $\beta$-lactamase (BLA) was first permuted and then inserted into maltose binding protein (MBP), binding of maltose induces conformational changes that trigger hydrolysis of nitrocefin into a red product. Plating cells expressing the switch on $\beta$-lactam antibiotics allows engineering of probes responsive to ligands other that maltose; (B) Nitrocefin hydrolysis catalyzed by $\beta$-lactamase produces a red product; (C) Firefly luciferase engineered to detect cAMP. Binding of analyte to RII $\beta$ B promotes conformational change that increases bioluminescence.

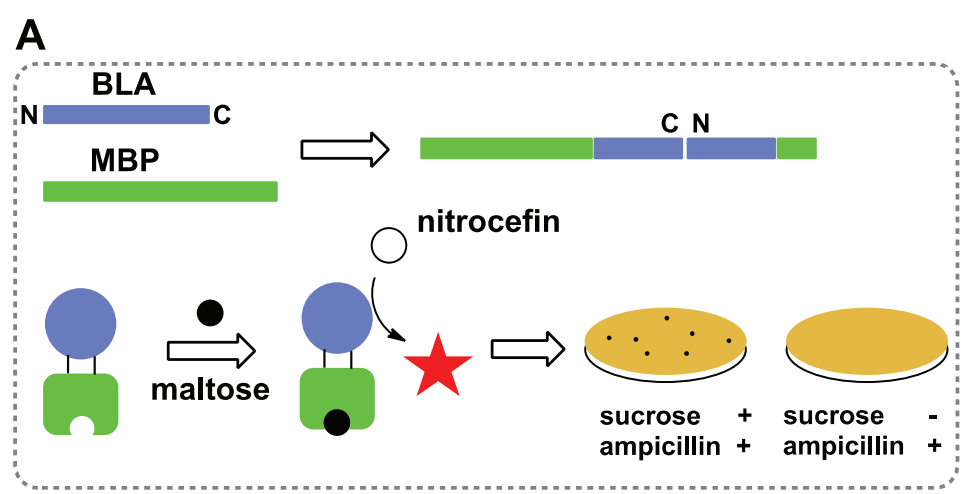

C

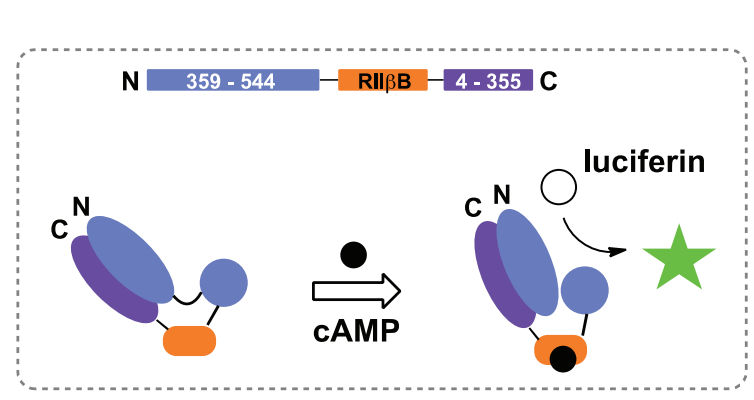

B<smiles>O=C(Cc1cccs1)NC1C(=O)N2C(C(=O)O)=C(/C=C/c3ccc([N+](=O)[O-])cc3[N+](=O)[O-])CS[C@H]12</smiles>

nitrocefin (yellow) hydrolysis

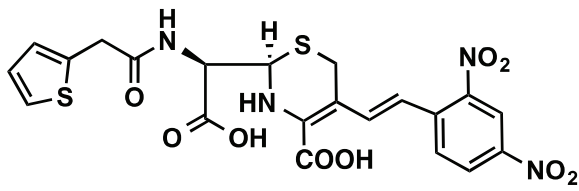

red 
Figure 4. Sensor design based on protein splicing. Ligand binding domain (ER LBD), intein, and $\beta$-galactosidase enzyme are fused together so that binding of the ligand activates splicing of the enzyme (A), which then catalyses X-gal hydrolysis and formation of a blue product $(\mathbf{B})$.

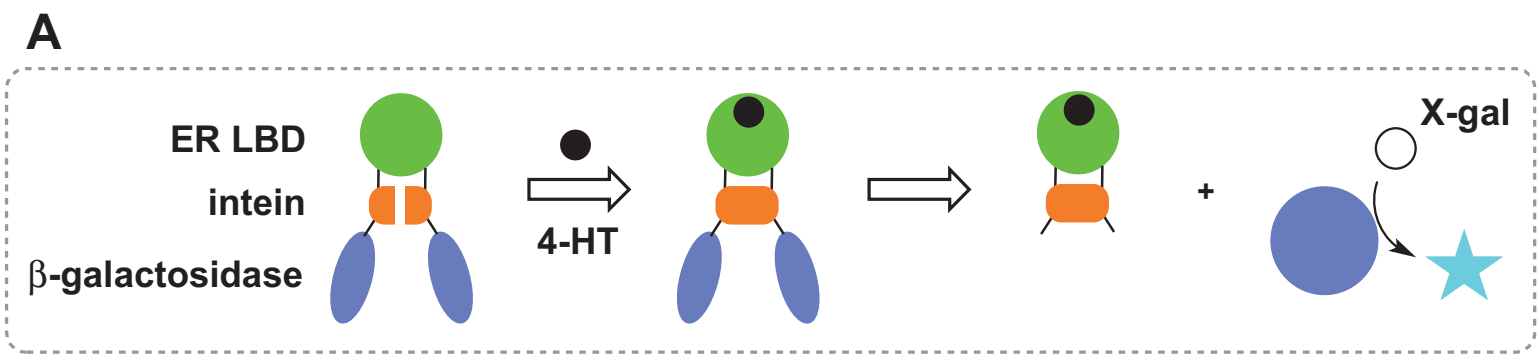

B

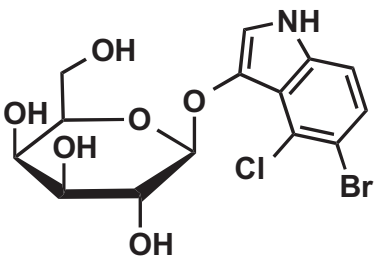

$X$-gal galactose

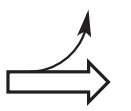

blue

\subsection{Chemical Rescue}

This method is based on introducing a mutation that disrupts structural integrity of the active site and leads to inactive enzyme. Addition of a small molecule restores structure and function of the enzyme. Deckert et al. designed a switch to modulate $\beta$-glycosidase activity by indole $[47,48]$ (Figure 5A). A single tryptophan located close to the active site was mutated to a glycine and the resulting protein had $\sim 700$-fold lower $\mathrm{k}_{\text {cat }} / \mathrm{K}_{\mathrm{M}}$ as compared to wild type enzyme. The crystal structure of this mutant showed that a key residue at the active site shifted to fill the cavity formed by the Trp to Gly mutation and thus moved away from the substrate. The added indole occupied the cavity and restored the enzyme's structure and function (as measured by hydrolysis of fluorescein di- $\beta$-D-galactopyranoside, FDG, Figure 5B). In this example the mutation was introduced very close to the active site, however the strategy described may be used for introducing mutations at a remote site given that disruption of the structure is relayed to the active site.

Lin et al. reprogrammed zinc finger transcription factor $\mathrm{C} 7$ to respond to small-molecule binding and turn on luciferase gene transcription [49]. The two critical residues (His125 and Phe116), which are responsible for zinc binding and hydrophobic packing, were mutated to glycine and alanine, respectively. These mutations significantly perturbed the integrity of DNA binding helix. A library of 250 small molecules was screened to identify molecules that complement mutations and rescue DNA binding function. One of the most successful candidates, 2-(4'-quinoline)benzimidazole induced luciferase activity by 18 -fold. Further studies by surface plasmon resonance demonstrated that interaction of this compound with the mutant zinc finger increased affinity of the mutant $\mathrm{C} 7$ to its cognate DNA sequence. 
Figure 5. Protein sensor designed using chemical rescue approach. (A) A single mutation changes the structure of the active site, rendering the enzyme inactive; (B) Addition of indole restores the structure and rescues the enzyme's ability to catalyze FDG hydrolysis to the wild type level.

A

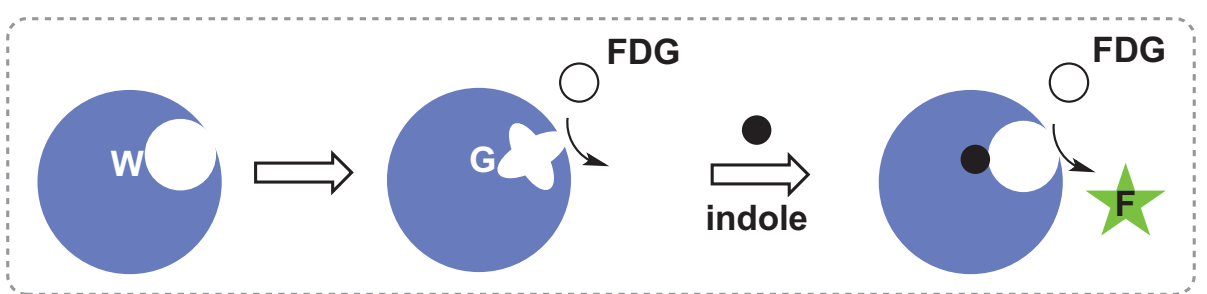

B

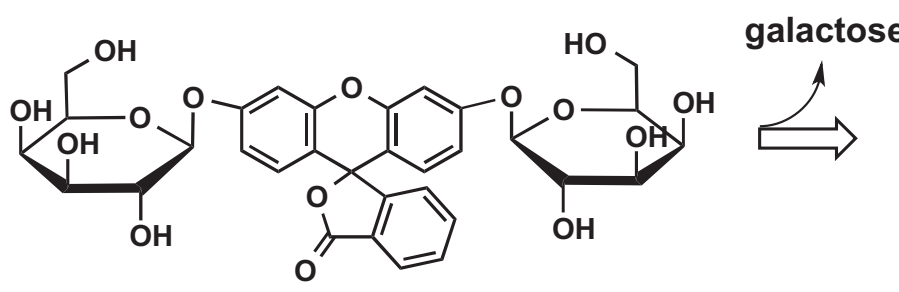

FDG

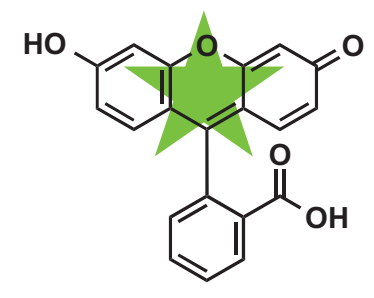

fluorescein

\subsection{De Novo Design of Catalytic Function}

Calmodulin $(\mathrm{CaM})$ is one of the most abundant eukaryotic regulatory proteins involved in many cellular processes. CaM consists of two independent helical domains connected by a linker. Each of the two domains has two EF-hand motifs. Calcium binding by EF-hand triggers a drastic conformational change resulting in formation of solvent exposed hydrophobic cavities in each of its domains. This unique ability was previously exploited to create several successful fluorescent switches, including pericams [3], cameleons [2] and camgaroos [4]. However, those sensors are not catalytically amplified as CaM has no enzymatic activity of its own. Korendovych et al. used computational protein design to introduce catalytic activity into this non-enzymatic scaffold. The $C$-terminal domain of CaM was chosen as a scaffold because of its naturally high affinity for $\mathrm{Ca}(\mathrm{II})$, high thermodynamic stability, presence of a cavity that can accommodate substrate, and its small size to facilitate preparation and NMR studies of the sensor. A single Glu residue introduced at the bottom of an otherwise hydrophobic pocket confers the ability to catalyze Kemp elimination on CaM and converts it into a catalytically amplified sensor for $\mathrm{Ca}(\mathrm{II})$, named AlleyCat [50] (Figure 6A). Kemp elimination is an excellent choice for a readout reaction as substrate is easily available and concentration of product can be measured spectrophotometrically (Figure 6B). In addition, there are no natural enzymes in E. coli that catalyze this reaction and therefore catalytic activity can be measured in crude cell lysates, a factor important for directed evolution. The catalytic efficiency of the original AlleyCat design was improved over 200-fold after 7 rounds of directed evolution [51]. Thus AlleyCat is an efficient catalytically amplified sensor for calcium that could be used both in vivo and in vitro. The key advantages of using the de novo protein design to create catalytically amplified sensors are: (1) catalytic reaction of choice can be used to amplify the signal; (2) both binding site and catalytic site can be evolved to improve selectivity 
and catalytic efficiency. To show that this approach can be extended to other metals, Mack et al. redesigned the EF-hand motif to sense trivalent metal ions by mutating two neutral residues in the $\mathrm{Ca}^{2+}$-binding loop to glutamates. The resulting protein (CuSeCat) has almost two orders of magnitude higher selectivity for trivalent metals as compared to calcium [52].

Figure 6. The general principle of $\mathrm{Ca}^{2+}$ detection using calmodulin (CaM) engineered to catalyze Kemp elimination. (A) CaM undergoes structural changes upon $\mathrm{Ca}^{2+}$ binding that lead to formation of a hydrophobic pocket. Introduction of catalytic residue Glu92 into this pocket enabled calmodulin to catalyze the Kemp elimination reaction (B).

A

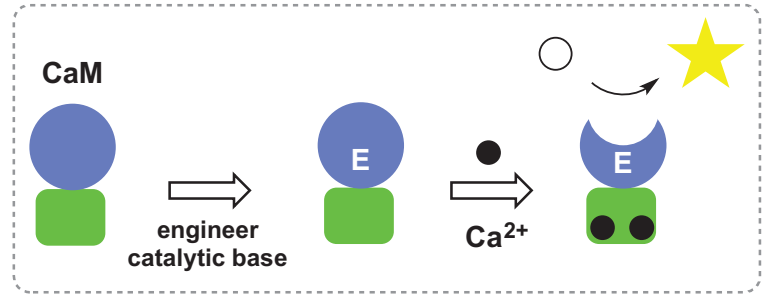

B

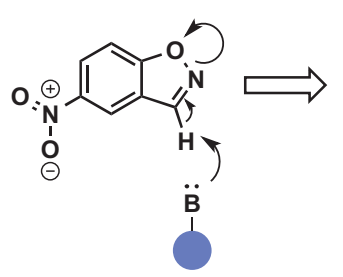

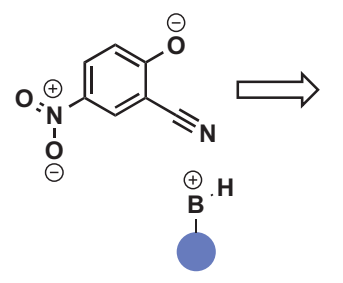

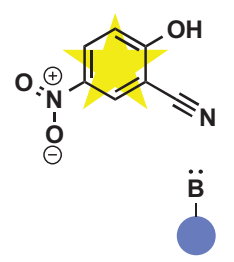

\subsection{Switches Based on Two-Component Systems}

Two-component signal transduction systems (TCSs) consist of histidine kinase (HK) and cytosolic response regulator (RR). Analyte binding at the extracellular part of $\mathrm{HK}$ results in conformational changes that send the signal across the membrane and trigger phosphorylation of histidine at the intracellular tail. An aspartate on the response regulator is then phosphorylated, which induces a response by up-regulating gene expression. In wild type pathways, periplasmic ribose-binding protein (RBP) binds ribose, which initiates a signal cascade that controls chemotaxis. Several studies from the Hellinga group showed that RBP can be redesigned to bind $\mathrm{Zn}$ (II) [53], trinitrotoluene, and L-lactate [54], and these receptors were introduced into TCS that regulates $\beta$-galactosidase gene (Figure 7A). The resulting synthetic TCSs were shown to regulate gene expression in response to extracellular ligands as measured by increased $\beta$-galactosidase activity (Figure 7B). However, it should be noted that these studies were later questioned as no binding of the designed receptors to their respective ligands could be detected experimentally [55].

More recently, Salmonella iron(III)-sensing TCS was modified to respond to lanthanide ions. The iron(III)-binding motif was replaced with a lanthanide binding sequence and the resulting hybrid TCS was shown to regulate expression of GFP fused to the corresponding promoter [56]. This work paves the way to engineered organisms for detection of metal ions in the environment.

While the TCS system approach relies on enzyme expression as a function of analyte concentration, it is possible to report the change in substrate concentration when enzyme concentration remains constant. Specifically, hydrolysis of exogenously added nitrocefin by periplasmic $\beta$-lactamase or hydrolysis of ONPG by cytoplasmic $\beta$-galactosidase was used to measure permeability of outer and inner membranes, respectively [57-59]. This strategy therefore may be used to sense small molecules that are capable of permeabilizing the membrane. 
Figure 7. Synthetic two-component pathway that combines redesigned receptor (blue) with chimeric histidine kinase (HK) consisting of periplasmic domain from chemotaxis sensor (pink) and cytoplasmic domain from osmosensor (grey). (A) This chimeric HK phosphorylates response regulator ( $R R$, grey) from osmosensor, which then turns on transcription of the $\beta$-galactosidase gene (green); (B) Reaction used to measure $\beta$-galactosidase activity. ONPG, 2-nitrophenyl- $\beta$-galactopyranoside.

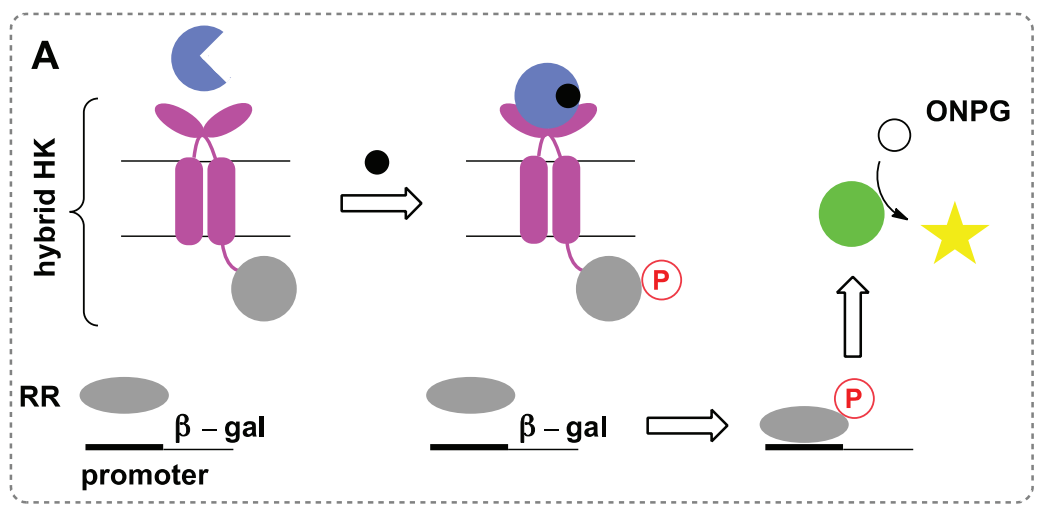

B

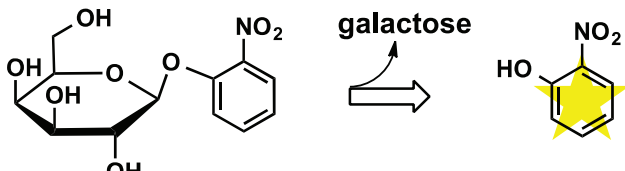

\section{Signal Amplification by Organometallic Catalysts}

In the following section we summarize recent successful reports on design of allosterically controlled organometallic catalysts with convenient colorimetric or fluorometric readouts supplementing extensive in-depth reviews on this subject [23,60-63].

\subsection{Switches Based on a Weak-Link Approach}

Using a weak-link approach $[64,65]$ Gianneschi et al. created a supramolecular reversible allosteric detection system with catalytically amplified signal that can be activated by small molecules such as $\mathrm{Cl}^{-}$and $\mathrm{CO}$ [66]. The recognition part of the sensor is comprised of metal ions ( $\mathrm{Rh}(\mathrm{I})$ or $\left.\mathrm{Cu}(\mathrm{I})\right)$ bound to flexible hemilabile ligands with sulfur and phosphorus as the donor atoms (Figure 8). The flexible portion of the ligand, which forms the catalytic part of the sensor, contains a $\mathrm{Zn}$-Salen complex that is not sterically accessible in the absence of $\mathrm{Cl}^{-}$and $\mathrm{CO}$. When $\mathrm{Cl}^{-}$or $\mathrm{CO}$ bind to the sensor, they displace the thioether sulfurs in the $\mathrm{Rh}(\mathrm{I})$ coordination sphere, while keeping stronger Rh-P bonds intact. The resulting coordination sphere rearrangement leads to an extension of the macrocycle cavity (shown as the open state in Figure 8) and subsequent exposure of the catalytic component of the sensor. The rearrangement turns on the catalysis of a transfer reaction between acetic anhydride and pyridyl carbinol. The rate of the reaction is 25 -fold higher relative to the background rate in the absence of $\mathrm{Cl}^{-}$and $\mathrm{CO}$. The readout is simplified by the presence of a $\mathrm{pH}$-sensitive fluorophore, which reports how much acetic acid was generated. Reversible switching of the sensor to the closed inactive state was achieved by purging the system with nitrogen or removing $\mathrm{CO}$ under vacuum. 
Figure 8. Allosterically controlled macrocycle catalyst designed through WLA. Recognition center is marked blue and catalytic center is in green. $\mathrm{CO}$ and $\mathrm{Cl}^{-}$binding breaks weak-link $\mathrm{Rh}-\mathrm{S}$ bonds and converts structure into a catalytically active "open" state.
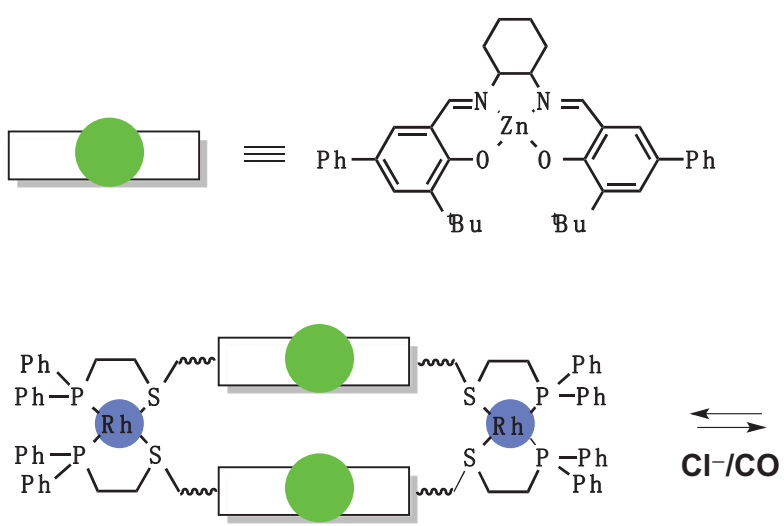

closed
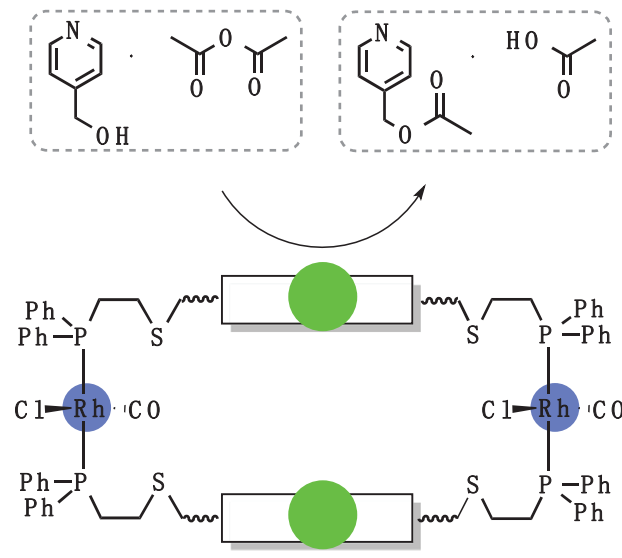

open

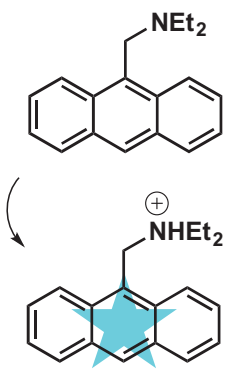

In another proof-of-concept study, Yoon et al. used a Zn-Salen based system, very similar to the one described above, for acetate detection with catalytic signal self-amplification [67]. Acetate binding to the $\mathrm{Rh}(\mathrm{I})$ center opens the macrocycle, initiating a catalytic reaction between acetic anhydride and pyridyl carbinol to produce more acetic acid. A pH-sensitive fluorophore-base then reacts with acetic acid to form acetate, which in turn self-amplifies the reaction. The system demonstrates that organometallic probes can be designed to amplify the signal via a cascade of additional catalytic cycles, similarly to polymerase chain reaction cascade. Furthermore, it was shown that phenanthroline can open the complex when $\mathrm{Rh}(\mathrm{I})$ is replaced with $\mathrm{Cu}(\mathrm{I})$ and therefore the design could be extended to detection of phenanthroline [68]. Using the same strategy another complex was designed that could reversibly operate in pseudo-aqueous conditions with good catalytic rate and turnover. Instead of the Zn-Salen motif, the macrocycle featured a Zn-pyridine-bisimine core with two zinc centers bridged by an acetate ion, which prevented substrate access to the catalyst [69]. As expected, no catalytic hydrolysis of 2-(hydroxypropyl)-p-nitrophenyl phosphate (HPNP) was observed in the closed state, however $\mathrm{CO} / \mathrm{Cl}^{-}$binding opened the macrocycle and increased the rate 100 -fold as measured by formation of colored $p$-nitrophenolate.

\subsection{Metal Sensors Based on Variable Affinity to Ligands}

Two catalytically amplified sensors for $\mathrm{Cu}(\mathrm{II})$ and $\mathrm{Cd}(\mathrm{II})$ were designed in the Anslyn lab based on Heck reaction [70,71]. The sensor for copper is based on the competition between $\mathrm{Cu}(\mathrm{II})$ and $\mathrm{Pd}$ (II) for polyaza cyclam ligand (PAC). When complexed with PAC, Pd(II) can not catalyze formation of fluorescent 3-methylindole via the Heck reaction. Added $\mathrm{Cu}(\mathrm{II})$ releases a certain amount of $\mathrm{Pd}(\mathrm{II})$, which after phosphine-mediated reduction to $\operatorname{Pd}(0)$ catalyzes formation of 3-methylindole (Figure 9A). Selectivity for $\mathrm{Cu}(\mathrm{II})$ is driven by high affinity of PAC ligand for this metal ion, as compared to other metal ions. A very similar strategy was applied to a design of $\mathrm{Cd}$ (II) sensor. A ligand 
selective for $\mathrm{Cd}(\mathrm{II}), 1,4,7,10,13$-pentaazacyclopentadecane, inactivated catalytic formation of fluorescent 7-diethylaminocoumarin. $\mathrm{Cd}(\mathrm{II})$ sequestered the ligand releasing $\operatorname{Pd}(\mathrm{II})$, which was then reduced in situ and catalyzed the fluorogenic Heck reaction.

Figure 9. Sensors for metals designed based on differences in ligand affinity. (A) $\mathrm{Cu}$ (II) is recognized by cyclam ligand (blue), release of $\mathrm{Pd}(\mathrm{II})$ and its in situ reduction by phosphine to catalytic $\mathrm{Pd}(0)$ (green) enables the Heck reaction; (B) Free $\mathrm{Cu}$ (II) displaced upon $\mathrm{Pb}$ (II) binding is reduced to $\mathrm{Cu}(\mathrm{I})$ which catalyzes formation of the FRET active product through Huisgen cycloaddition.
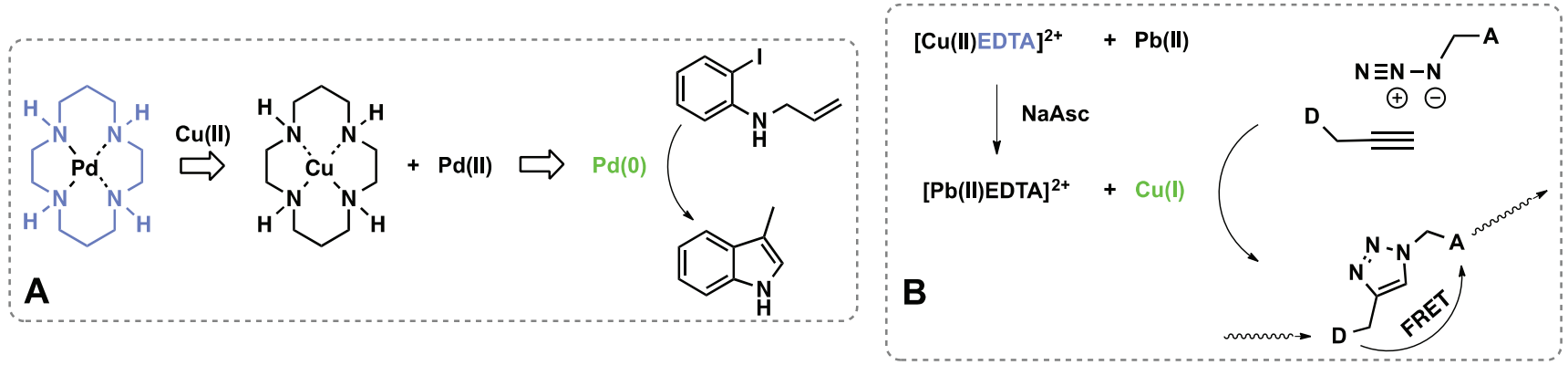

In another study, azide alkyne Huisgen cycloaddition catalyzed by $\mathrm{Cu}(\mathrm{I})$ was used as a platform to report presence of $\mathrm{Pb}(\mathrm{II})$ ions [72]. EDTA coordinates $\mathrm{Cu}$ (II) and prevents its reduction to catalytically active $\mathrm{Cu}(\mathrm{I})$. Addition of $\mathrm{Pb}(\mathrm{II})$ releases $\mathrm{Cu}(\mathrm{II})$, which after reaction with ascorbate catalyzes a cycloaddition reaction between azide and alkyne attached to fluorophores (Figure 9B). Förster resonance energy transfer (FRET) between anthracene (donor, D) and coumarin (acceptor, A) correlates with the amount of product formed and reports the concentration of the analyte.

\subsection{Sensors Based on Auto Amplification Mechanism}

Sensors for $\mathrm{H}_{2} \mathrm{O}_{2}$ [73] and fluoride [74] were designed in the Shabat group using decomposition of dendrimers through a chain reaction. In this approach the analyte removes a triggering group, which in turn produces more analyte and initiates additional reaction cycles and ultimately results in exponential growth of the signal generated by a reporter molecule. Two components were used to achieve signal amplification for hydrogen peroxide detection (Figure 10A). A chain reaction is initiated when a $\mathrm{H}_{2} \mathrm{O}_{2}$ molecule cleaves phenylboronic acid (trigger) of the reagent component and releases two choline molecules. Choline oxidase (COX) present in the solution oxidizes each choline molecule with formation of two $\mathrm{H}_{2} \mathrm{O}_{2}$ molecules. When $\mathrm{H}_{2} \mathrm{O}_{2}$ removes phenylboronic acid group from a reporter component, yellow 5-amino-2-nitrobenzoic acid is released and can be detected by spectrophotometer.

A similar approach has been applied by Baker et al. who developed an autocatalytic system for palladium detection that also requires two components for detection and amplification [75]. The detection reagent reacts with palladium to release fluoride, which then triggers an autocatalytic reaction with the signal amplification reagent producing a product (Figure 10B). 
Figure 10. Sensors for $\mathrm{H}_{2} \mathrm{O}_{2}$ and $\mathrm{Pd}$ (II) that utilize autocatalytic signal amplification. (A) A molecule of $\mathrm{H}_{2} \mathrm{O}_{2}$ triggers cleavage and disassembly of reagent component, the process which in combination with $\mathrm{COX}$ catalysis produces many more $\mathrm{H}_{2} \mathrm{O}_{2}$ and initiates a dendritic chain reaction; (B) $\mathrm{Pd}(\mathrm{II})$ reacts with detection reagent with release of $\mathrm{F}^{-}$, which in turn reacts with amplification reagent and produces more $\mathrm{F}^{-}$in an autocatalytic fashion.
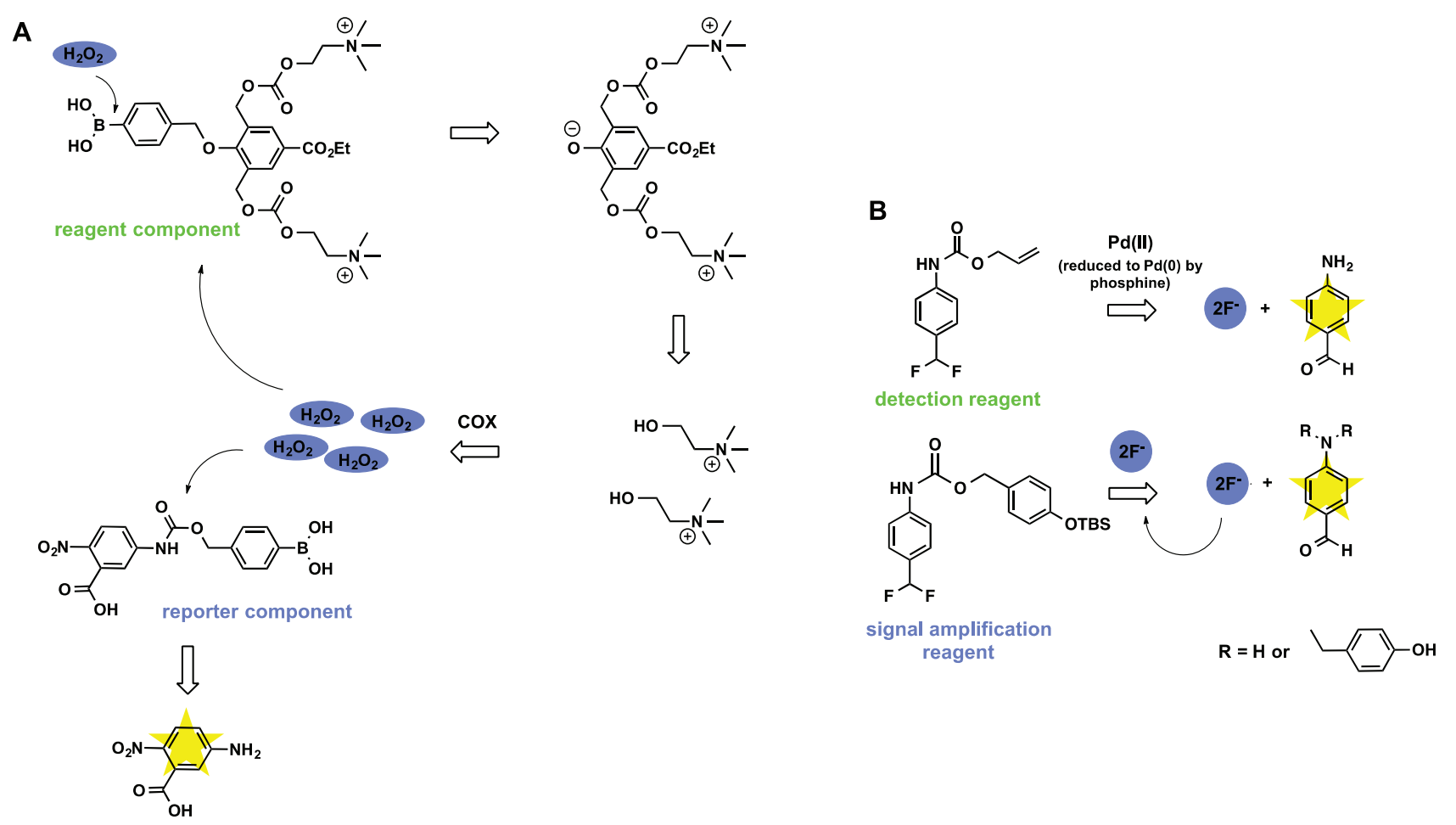

\section{Conclusions}

The field of sensor design has grown significantly over the past decade due to interest in the detection of disease biomarkers, metal homeostasis, environmental pollutants and explosives. Although many sensitive methods for small molecule detection already exist (e.g., ICP, ITC, SPR), they often require sophisticated instrumentation and timely sample preparation. Catalytically amplified sensors provide advantages of quick signal readout based on formation of colored or fluorescent product that can be clearly observed visually and/or quantitatively measured by simple spectrophotomer/fluorometer. These qualities are indispensable when working at remote sites or without access to instrumentation.

Here we have reviewed a number of successful approaches for the design of catalytically amplified sensors. While promising results have been achieved in the field of organometallic sensors, their relatively low selectivity, high background reaction rates and narrow solvent compatibility limit their practical applicability. On the other hand, protein-based sensors are more robust and can be optimized by directed evolution. However, current state-of-art protein-based catalytically amplified sensors still mostly utilize natural machinery and existing allosteric interactions. Recent developments in de novo protein design give hope that this weakness will soon be overcome, providing essentially limitless abilities for cheap, efficient and biocompatible sensors for small molecules. 


\section{Acknowledgments}

This work was supported in part by Grant Number 1332349 from the NSF-EFRI and an ORAU Ralph E. Powe Junior Faculty Enhancement award to Ivan V. Korendovych.

\section{Author Contributions}

Olga V. Makhlynets and Ivan V. Korendovych wrote the manuscript.

\section{Conflicts of Interest}

The authors declare no conflict of interest.

\section{References}

1. Stratton, M.M.; McClendon, S.; Eliezer, D.; Loh, S.N. Structural characterization of two alternate conformations in a calbindin D9k-based molecular switch. Biochemistry 2011, 50, 5583-5589.

2. Miyawaki, A.; Llopis, J.; Heim, R.; McCaffery, J.M.; Adams, J.A.; Ikura, M.; Tsien, R.Y. Fluorescent indicators for $\mathrm{Ca}^{2+}$ based on green fluorescent proteins and calmodulin. Nature 1997, $388,882-887$.

3. Nagai, T.; Sawano, A.; Park, E.S.; Miyawaki, A. Circularly permuted green fluorescent proteins engineered to sense $\mathrm{Ca}^{2+}$. Proc. Natl. Acad. Sci. USA 2001, 98, 3197-3202.

4. Baird, G.S.; Zacharias, D.A.; Tsien, R.Y. Circular permutation and receptor insertion within green fluorescent proteins. Proc. Natl. Acad. Sci. USA 1999, 96, 11241-11246.

5. De Lorimier, R.M.; Smith, J.J.; Dwyer, M.A.; Looger, L.L.; Sali, K.M.; Paavola, C.D.; Rizk, S.S.; Sadigov, S.; Conrad, D.W.; Loew, L.; et al. Construction of a fluorescent biosensor family. Protein Sci. 2002, 11, 2655-2675.

6. Yang, C.J.; Jockusch, S.; Vicens, M.; Turro, N.J.; Tan, W. Light-switching excimer probes for rapid protein monitoring in complex biological fluids. Proc. Natl. Acad. Sci. USA 2005, 102, 17278-17283.

7. Fehr, M.; Rfommer, W.B.; Lalonde, S. Visualization of maltose uptake in living yeast cells by fluorescent nanosensors. Proc. Natl. Acad. Sci. USA 2002, 99, 9846-9851.

8. Medintz, I.L.; Deschamps, J.R. Maltose-binding protein: A versitile platform for prototyping biosensing. Curr. Opin. Biotechnol. 2006, 17, 17-27.

9. Mochizuki, N.; Yamashita, S.; Kurokawa, K.; Ohba, Y.; Nagal, T.; Miyawaki, A.; Matsuda, M. Spatio-temporal images of growth-factor-induced activation of Ras and Rap1. Nature 2001, 411, 1065-1068.

10. Tyagi, S.; Kramer, F.R. Molecular beacons: Probes that fluoresce upon hybridization. Nat. Biotechol. 1996, 14, 303-308.

11. Vallée-Bélisle, A.; Plaxco, K.W. Structure-switching biosensors: Inspired by nature. Curr. Opin. Struct. Biol. 2010, 20, 518-526.

12. Monod, J.; Changeux, J.-P.; Jacob, F. Allosteric proteins and cellular control systems. J. Mol. Biol. 1963, 6, 306-329. 
13. Engvall, E.; Perlmann, P. Enzyme-linked immunosorbent assay (ELISA). Quantitative assay of immunoglobin G. Immunochemistry 1971, 8, 871-874.

14. Gosling, J.P. A decade of development in immunoassay methodology. Clin. Chem. 1990, 36, $1408-1427$.

15. Van Weemen, B.K.; Schuurs, A.H.W.M. Immunoassay using antigen-enzyme conjugates. FEBS Lett. 1971, 15, 232-236.

16. Saiki, R.K.; Scharf, S.; Faloona, F.; Mullis, K.B.; Horn, G.T.; Erlich, H.A.; Arnheim, N. Enzymatic amplification of beta-globin genomic sequences and restriction site analysis for diagnosis of sickle cell anemia. Science 1985, 230, 1350-1354.

17. Saiki, R.K.; Bugawan, T.L.; Horn, G.T.; Mullis, K.B.; Erlich, H.A. Analysis of enzymatically amplified beta-globin and HLA-DQ $\alpha$ DNA with allele-specific oligonucleotide probes. Nature 1986, 324, 163-166.

18. Sano, T.; Smith, C.T.; Cantor, C.R. Immuno-PCR: Very sensitive antigen detection by means of specific antibody-DNA conjugates. Science 1992, 258, 120-122.

19. Niemeyer, C.M.; Adler, M.; Wacker, R. Detecting antigens by quantitative immuno-PCR. Nat. Protoc. 2007, 2, 1918-1930.

20. Niemeyer, C.M.; Adler, M.; Wacker, R. Immuno-PCR: High sensitivity detection of proteins by nucleic acid amplification. Trends Biotechnol. 2005, 23, 208-216.

21. Heid, C.A.; Stevens, J.; Livak, K.J.; Williams, P.M. Real time quantitative PCR. Genome Res. 1996, 6, 986-994.

22. Scrimin, P.; Prins, L.J. Sensing through signal amplification. Chem. Soc. Rev. 2011, 40, 4488-4505.

23. Zhu, L.; Anslyn, E.V. Signal ampliifcation by allosteric catalysis. Angew. Chem. Int. Ed. 2006, 45, 1190-1196.

24. Saghatelian, A.; Guckian, K.M.; Thayer, D.A.; Ghadiri, M.R. DNA detection and signal amplification via an engineered allosteric enzyme. J. Am. Chem. Soc. 2003, 125, 344-345.

25. Mitrea, D.M.; Parsons, L.S.; Loh, S.N. Engineering an artificial zymogen by alternate frame protein folding. Proc. Natl. Acad. Sci. USA 2010, 107, 2824-2829.

26. Hartig, J.S.; Grüne, I.; Najafi-Shoushtari, H.; Famulok, M. Sequence-specific detection of micrornas by signal-amplifying ribozymes. J. Am. Chem. Soc. 2004, 126, 722-723.

27. Graf, N.; Krämer, R. Enzymatic amplification in a bioinspired, autonomous signal cascade. Chem. Commun. 2006, 4375-4376.

28. Graf, N.; Göritz, M.; Krämer, R. A metal-ion-releasing probe for DNA detection by catalytic signal amplification. Angew. Chem. Int. Ed. 2006, 45, 4013-4015.

29. Miranda, O.R.; Chen, H.-T.; You, C.-C.; Mortenson, D.E.; Yang, X.-C.; Bunz, U.H.F.; Rotello, V.M. Enzyme-amplified array sensing of proteins in solution and in biofluids. J. Am. Chem. Soc. 2010, 132, 5285-5289.

30. Bonomi, R.; Cazzolaro, A.; Sansone, A.; Scrimin, P.; Prins, L.J. Detection of enzyme activity through catalytic signal amplification with functionalized gold nanoparticles. Angew. Chem. Int. Ed. 2011, 50, 2307-2312.

31. Wright, C.M.; Heins, R.A.; Ostermeier, M. As easy as flipping a switch? Curr. Opin. Chem. Biol. 2007, 11, 342-346. 
32. Ambroggio, X.I.; Kuhlman, B. Design of protein conformational switches. Curr. Opin. Struct. Biol. 2006, 16, 525-530.

33. Ha, J.-H.; Loh, S.N. Protein conformational switches: From nature to design. Chem. Eur. J. 2012, $18,7984-7999$.

34. Ostermeier, M. Designing switchable enzymes. Curr. Opin. Struct. Biol. 2009, 19, 442-448.

35. Koide, S. Generation of new protein functions by nonhomologous combinations and rearrangements of domains and modules. Curr. Opin. Biotechnol. 2009, 20, 398-404.

36. Stratton, M.M.; Loh, S.N. Converting a protein into a switch for biosensing and functional regulation. Protein Sci. 2011, 20, 19-29.

37. Ostermeier, M. Engineering allosteric protein switches by domain insertion. Protein Eng. Des. Sel. 2005, 18, 359-364.

38. Kim, S.B.; Otani, Y.; Umezawa, Y.; Tao, H. Bioluminescence indicator for determining protein-protein interactions using intramolecular complementation of split click beetle luciferase. Analyt. Chem. 2007, 79, 4820-4826.

39. Kim, S.B.; Umezawa, Y.; Kanno, K.A.; Tao, H. An integrated-molecule-format multicolor probe for monitoring multiple activities of a bioactive small molecule. ACS Chem. Biol. 2008, 3 , 359-372.

40. Guntas, G.; Mitchell, S.F.; Ostermeier, M. A molecular switch created by in vitro recombination of nonhomologous genes. Chem. Biol. 2004, 11, 1483-1487.

41. Guntas, G.; Mansell, T.J.; Kim, J.R.; Ostermeier, M. Directed evolution of protein switches and their application to the creation of ligand-binding proteins. Proc. Natl. Acad. Sci. USA 2005, 102, 11224-11229.

42. Edwards, W.R.; Busse, K.; Allemann, R.K.; Jones, D.D. Linking the functions of unrelated proteins using a novel directed evolution domain insertion method. Nucleic Acids Res. 2008, doi:10.1093/nar/gkn363.

43. Edwards, W.R.; Williams, A.J.; Morris, J.L.; Baldwin, A.J.; Allemann, R.K.; Jones, D.D. Regulation of beta-lactamase activity by remote binding of heme: Functional coupling of unrelated proteins through domain insertion. Biochemistry 2010, 49, 6541-6549.

44. Fan, F.; Binkowski, B.F.; Butler, B.L.; Stecha, P.F.; Lewis, M.K.; Wood, K.V. Novel genetically encoded biosensors using firefly luciferase. ACS Chem. Biol. 2008, 3, 346-351.

45. Buskirk, A.R.; Ong, Y.-C.; Gartner, Z.J.; Liu, D.R. Directed evolution of ligand dependence: Small-molecule-activated protein splicing. Proc. Natl. Acad. Sci. USA 2004, 101, 10505-10510.

46. Skretas, G.; Wood, D.W. Regulation of protein activity with small-molecule-controlled inteins. Protein Sci. 2005, 14, 523-532.

47. Deckert, K.; Budiardjo, S.J.; Brunner, L.C.; Lovell, S.; Karanicolas, J. Designing alllosteric control into enzymes by chemical rescue of structure. J. Am. Chem. Soc. 2012, 134, 10055-10060.

48. Xia, Y.; DiPrimo, N.; Keppel, T.R.; Vo, B.; Fraser, K.; Battaile, K.P.; Egan, C.; Bystroff, C.; Lovell, S.; Weis, D.D.; et al. The designability of protein switches by chemical rescue of structure: Mechanism of inactivation and reactivation. J. Am. Chem. Soc. 2013, 135, 18840-18849.

49. Lin, Q.; Barbas, C.F., III; Schultz, P.G. Small-molecule switches for zinc finger transcription factors. J. Am. Chem. Soc. 2002, 125, 612-613. 
50. Korendovych, I.V.; Kulp, D.W.; Wu, Y.; Cheng, H.; Roder, H.; DeGrado, W.F. Design of a switchable eliminase. Proc. Natl. Acad. Sci. USA 2011, 108, 6823-6827.

51. Moroz, O.V.; Moroz, Y.S.; Wu, Y.; Olsen, A.B.; Cheng, H.; Mack, K.L.; McLaughlin, J.M.; Raymond, E.A.; Zhezherya, K.; Roder, H.; et al. A single mutation in a regulatory protein produces evolvable allosterically regulated catalyst of nonnatural reaction. Angew. Chem. Int. Ed. 2013, 52, 6246-6249.

52. Mack, K.L.; Moroz, O.V.; Moroz, Y.S.; Olsen, A.B.; McLaughlin, J.M.; Korendovych, I.V. Reprogramming EF-hands for design of catalytically amplified lanthanide sensors. J. Biol. Inorg. Chem. 2013, 18, 411-418.

53. Dwyer, M.A.; Looger, L.L.; Hellinga, H.W. Computational design of a $\mathrm{Zn}^{2+}$ receptor that controls bacterial gene expression. Proc. Natl. Acad. Sci. USA 2003, 100, 11255-11260.

54. Looger, L.L.; Dwyer, M.A.; Smith, J.J.; Hellinga, H.W. Computational design of receptor and sensor proteins with novel functions. Nature 2003, 423, 185-190.

55. Schreier, B.; Stumpp, C.; Wiesner, S.; Höcker, B. Computational design of ligand binding is not a solved problem. Proc. Natl. Acad. Sci. USA 2009, 106, 18491-18496.

56. Liang, H.; Deng, X.; Bosscher, M.; Ji, Q.; Jensen, M.P.; He, C. Enginering bacterial two-component system PmrA/PmrB to sense lanthanide ions. J. Am. Chem. Soc. 2013, 135, 2037-2039.

57. Mensa, B.; Kim, Y.H.; Choi, S.; Scott, R.; Caputo, G.A.; DeGrado, W.F. Antibacterial mechanism of action of arylamide foldamers. Antimicrob. Agents Chemother. 2011, 55, 5043-5053.

58. Hancock, R.E.W.; Wong, P.W. Compounds which increase the permeability of the pseudomonas aeruginosa outer membrane. Antimicrob. Agents Chemother. 1984, 26, 48-52.

59. Gibney, K.A.; Sovadinova, I.; Lopez, A.I.; Urban, M.; Ridgway, Z.; Caputo, G.A.; Kuroda, K. Poly(ethylene imine)s as antimicrobial agents with selective activity. Macromol. Biosci. 2012, 12, 1279-1289.

60. Wiester, M.J.; Ulmann, P.A.; Mirkin, C.A. Enzyme mimics based upon supramolecular coordination chemistry. Angew. Chem. Int. Ed. 2011, 50, 114-137.

61. Kremer, C.; Lützen, A. Artificial allosteric receptors. Chem. Eur. J. 2013, 19, 6162-6196.

62. Kovbasyuk, L.; Krämer, R. Allosteric supramolecular receptors and catalysts. Chem. Rev. 2004, 104, 3161-3187.

63. Raynal, M.; Ballester, P.; Vidal-Ferran, A.; van Leeuwen, P.W.N.M. Supramolecular catalysis. Part 2: Artificial enzyme mimics. Chem. Soc. Rev. 2014, 43, 1734-1787.

64. Gianneschi, N.C.; Masar, M.S., III; Mirkin, C.A. Development of a coordination chemistry-based approach for functional supramolecular structures. Acc. Chem. Res. 2005, 38, 825-837.

65. Holliday, B.J.; Mirkin, C.A. Strategies for the construction of supramolecular compounds through coordination chemistry. Angew. Chem. Int. Ed. 2001, 40, 2022-2043.

66. Gianneschi, N.C.; Nguyen, S.T.; Mirkin, C.A. Signal amplification and detection via a supramolecular allosteric catalyst. J. Am. Chem. Soc. 2005, 127, 1644-1645.

67. Yoon, H.J.; Mirkin, C.A. PCR-like cascade reactions in the context of an allosteric enzyme mimic. J. Am. Chem. Soc. 2008, 130, 11590-11591.

68. Masar, M.S., III; Gianneschi, N.C.; Oliveri, C.G.; Stern, C.L.; Nguyen, S.T.; Mirkin, C.A. Allosterically regulated supramolecular catalysis of acyl transfer reactions for signal amplification and detection of small molecules. J. Am. Chem. Soc. 2007, 129, 10149-10158. 
69. Yoon, H.J.; Heo, J.; Mirkin, C.A. Allosteric regulation of phosphate diester transesterification based upon a dinuclear zinc catalyst assembled via the weak-link approach. J. Am. Chem. Soc. 2007, 129, 14182-14183.

70. Wu, Q.; Anslyn, E.V. Catalytic signal amplification using a heck reaction. An axample in the fluorescence sensing of Cu(II). J. Am. Chem. Soc. 2004, 126, 14682-14683.

71. Wu, Q.; Anslyn, E.V. Heavy metal analysis using a heck-catalyzed cyclization to create coumarin. J. Mat. Chem. 2005, 15, 2815-2819.

72. Zhu, L.; Lynch, V.M.; Anslyn, E.V. Fret induced by an "allosteric" cycloaddition reaction regulated with exogenous inhibitor and effectors. Tetrahedron 2004, 60, 7267-7275.

73. Sella, E.; Lubelski, A.; Klafter, J.; Shabat, D. Two-component dendritic chain reactions: Experiment and theory. J. Am. Chem. Soc. 2010, 132, 3945-3952.

74. Perry-Feigenbaum, R.; Sella, E.; Shabat, D. Autoinductive exponential signal amplification: A diagnostic probe for direct detection of fluoride. Chem. Eur. J. 2011, 17, 12123-12128.

75. Baker, M.S.; Phillips, S.T. A two-component small molecule system for activity-based detection and signal amplification: Application to the visual detection of threshold levels of $\mathrm{Pd}(\mathrm{II})$. J. Am. Chem. Soc. 2011, 133, 5170-5173.

(C) 2014 by the authors; licensee MDPI, Basel, Switzerland. This article is an open access article distributed under the terms and conditions of the Creative Commons Attribution license (http://creativecommons.org/licenses/by/3.0/). 